\title{
Prevalence and Correlates of Glucose Homeostasis Abnormalities in the Far-North Region Cameroon
}

\section{Daniel Lemogoum ${ }^{1,2,3}$, William Ngatchou ${ }^{1,2}$, Elysée Claude Bika Lele ${ }^{3,4}$, Pierre Amta ${ }^{3}$, Philippe Van de Borne ${ }^{2}$, Marc Leeman², Philippe Donnen5 ${ }^{5}$ Nicolas Preumont ${ }^{2}$, Jean Paul Degaute ${ }^{2}$, Michel Hermans ${ }^{6}$}

\author{
${ }^{1}$ Faculty of Medicine and Pharmaceutical Sciences, University of Douala, Douala, Cameroon \\ ${ }^{2}$ ULB-Erasme Hospital, Free Brussels University, Brussels, Belgium \\ ${ }^{3}$ Cameroon Heart Foundation, Douala, Cameroon \\ ${ }^{4}$ Medical Research Centre, Institute of Medical Research and Medicinal Plants Studies, Yaoundé, Cameroon \\ ${ }^{5}$ School of Public Health, Free Brussels University, Brussels, Belgium \\ ${ }^{6}$ Endocrinology and Nutrition Unit, Cliniques Universitaires St-Luc, Université Catholique de Louvain, \\ Brussels, Belgium \\ Email: *dlems2002@yahoo.fr
}

How to cite this paper: Lemogoum, D. Ngatchou, W., Lele, E.C.B., Amta, P., Van de Borne, P., Leeman, M., Donnen, P., Preumont, N., Degaute, J.P. and Hermans, M. (2018) Prevalence and Correlates of Glucose Homeostasis Abnormalities in the Far-North Region Cameroon. Open Journal of Preventive Medicine, 8, 6-20. https://doi.org/10.4236/ojpm.2018.81002

Received: December 30, 2017

Accepted: January 28, 2018

Published: January 31, 2018

Copyright (C) 2018 by authors and Scientific Research Publishing Inc. This work is licensed under the Creative Commons Attribution International License (CC BY 4.0).

http://creativecommons.org/licenses/by/4.0/

\begin{abstract}
Background: Evidence indicates a growing burden of glucose homeostasis abnormalities (namely type 2 diabetes mellitus (T2DM) and prediabetes) in Cameroun. The aim of this study was to assess the prevalence and correlates of glucose homeostasis abnormalities (GHA) in the Far-North region of Cameroon, where these variables have not been explored so far. Methods: We included in this population-based cross-sectional survey 461 participants living urban area (Maroua) and 428 dwellers living in rural area (Tokombere) aged at least 18 years, using a multistage-cluster sampling frame. In all participants, we recorded sociodemographic, medical history, clinical data and fasting blood (capillary) glucose (FBG). Diabetes was considered for FBG $\geq$ $126 \mathrm{mg} / \mathrm{dL}$ or being on glucose-lowering medications, and impaired fasting glycemia (IFG) for FBG 100 - $125 \mathrm{mg} / \mathrm{dL}$. Results: The overall age-standardized prevalence of GHA, IFG and diabetes was $33.6 \%, 21.7 \%$ and $11.9 \%$, respectively. Those data were similar between urban and rural areas. Determinants of GHA were age, overweight/obesity, abdominal obesity and hypertension. IFG was only related to abdominal obesity, while diabetes was related to age, family history of diabetes, overweight/obesity, abdominal obesity and hypertension. Conclusion: Glucose homeostasis abnormalities are alarmingly high in Far North Cameroon. Efforts are needed to promote healthier lifestyles and initiate diabetes-screening campaigns in Cameroon.
\end{abstract}




\section{Keywords}

Glucose Homeostasis Abnormalities, Diabetes, Prediabetes, Far-North

Region, Cameroon, Urban, Rural

\section{Introduction}

Diabetes is one of commonest metabolic disease, rapidly rising in developed and developing countries [1]. It is estimated 422 million people worldwide are affected with diabetes [2] and this number is expected to rise to 592 millions in 2035 [3]. An epidemiological study on a pooled data of 2.7 million adults shows that the age-standardized mean fasting plasma glucose (FPG) has risen by 0.1 mmol/L from 1980 to 2008 [1]. This increase in FPG reflects an increase in glucose homeostasis abnormalities (namely type 2 diabetes mellitus (T2DM) and prediabetes). In low-and-middle incomes countries, a $69 \%$ increase in the prevalence of diabetes is foreseen between 2010 and 2030, compared to a $20 \%$ increase in developed countries [4] [5].

Prediabetes is an intermediate state characterized by impaired fasting glycemia (IFG) or impaired glucose tolerance (IGT). Prediabetes is a specific condition usually preceding T2DM, associated with increased risk for incident cardiovascular disease (CVD), as is the case with the common form of T2DM associated with obesity and the metabolic syndrome [6] [7] [8]. T2DM is a progressive condition, characterized by irreversible loss of insulin secretion over years. It usually occurs after a stage of prediabetes, in the absence of preventive intervention to delay this transition. The prevalence of IFG in sub-Saharan Africa (SSA) varies from $2.2 \%$ to $16 \%$ in different settings, and is likely to increase if nothing is done to curb its rise. A major factor underlying the increase in T2DM in SSA is rapid and uncontrolled urbanization, which is a driving force for most of the modifiable risk factors such as obesity, hypertension, reduced physical activity, sarcopenia, and increased tobacco and alcohol consumption [9] [10] [11].

According to the International Diabetes Federation (IDF), nearly half a million people are living with diabetes in Cameroon, corresponding to a $5.9 \%$ prevalence, and there were more than 6500 deaths attributable to diabetes in 2013 [3]. Studies conducted in Cameroon show a higher prevalence of T2DM and glucose abnormalities (GHA) in urban compared to rural areas [12]. However, most of those studies were conducted in southern and central regions of Cameroon. To the best of our knowledge, no study has addressed the burden of T2DM and IFG in the Far-North region of Cameroon, which faces one of the highest levels of poverty nationwide. The aim of this study was to determine the prevalence and determinants of glucose homeostasis abnormalities (GHA) in Cameroon's Far-North area.

\section{Patients and Methods}

This was a cross sectional population-based survey conducted from November 
2014 to April 2015. The survey was conducted in the health district of Maroua 1 (urban area) and Tokombere (rural area) in the Far-North region of Cameroon, which has an estimated population of 3,111,792 inhabitants, distributed over $34,263 \mathrm{~km}^{2}$ [13]. Study population ecologic settings and characteristics have been described elsewhere [14].

A census was conducted jointly by the local administrative and health authorities and our research team to map out the distribution of the population of the two health districts, and all households were identified. The minimum sample size was calculated using the following Lorenz formula: $z^{2} x p(1-p) / e^{2}$, with $z$ as confidence level, $\mathrm{p}$ as prevalence of diabetes and e as precision. Using a $5.9 \%$ prevalence of diabetes in Cameroon described by IDF [3], we calculated a sample size of 237 for a 95\% confident interval and 3\% precision. Participants were recruited using a three-stage sampling strategy with Maroua and Tokombere health districts as the first strata, neighborhood as the second strata and households as the third strata. Full details on sampling strategies have been published elsewhere [14]. A total of 929 participants (486 in Maroua and 443 in Tokombere) were encountered in the 645 households. Twenty-five participants in Maroua and 15 in Tokombere refused to participate in the survey, and finally 889 participants were enrolled (461 in Maroua and 428 in Tokombere). The survey participation rates in Maroua and Tokombere were $94.8 \%$ and $96.5 \%$, respectively. Pregnant women were excluded.

Participation to the study was voluntary. All eligible participants were informed about the goals, the importance and the benefits of the study. Each participant gave informed consent by signing or thumbprinting two consent forms, one of which was given to the participant. All participants received individual feedback on the results of their examination, and were referred whenever necessary to Tokombere and or Maroua district hospitals for appropriate medical follow up. All study participants received on-site counseling on healthy lifestyles. Data were anonymized for statistical analysis. Ethical approval of the study protocol was granted by the Institutional Review Board of Douala University and by Cameroon's National Ethics Committee.

\subsection{Data Collection}

The survey was conducted by trained observers simultaneously in Tokombere and Maroua city. Data collection and FBG measurements were performed in participants' households. During home visits, survey officers administered a structured questionnaire to the participants in a secluded place of the household. The questionnaire assessed socio-demographic variables, education level, history of diabetes, prevalent CVDs, current glucose-lowering medications, smoking habits, alcohol intake, weekly consumption of vegetables and fruits, and physical activity. Tobacco use was defined as never, former or current smoker [15]. Alcohol drinking was defined as having at least one alcoholic beverage per week. Fruit and vegetables consumption was defined as follow: insufficient if con- 
sumption or either fruit or vegetables was $<5$ servings per day [16]. Education was categorized as illiterate (never attended school); primary school (1 to 7 years), secondary or higher school (7 to 14 years); and university level (>14 years successful cumulative education). Level of physical activity (PA) was assessed using the Global Physical Activity Questionnaire version 2 (GPAQ-2) developed by the WHO for PA surveillance in developing countries [17]. The questionnaire consists of 16 questions covering moderate- and vigorous-intensity PA participation in three domains, PA at work, PA for commuting (travel to and from places, and which are not part of work), and recreational activities. For each physical activity, duration, frequency and intensity were assessed. Participants were categorized into low PA vs regular PA including moderate and high PA groups.

Physical examination included blood pressure (BP), heart rate (HR), waist circumference (WC), weight and height. Body mass index (BMI) was calculated as weight in kilograms divided by the square of height in meter $\left(\mathrm{kg} / \mathrm{m}^{2}\right)$. Overweight was defined as BMI $\geq 25 \mathrm{~kg} / \mathrm{m}^{2}$, and obesity as BMI $>30 \mathrm{~kg} / \mathrm{m}^{2}$. Abdominal obesity was defined as $\mathrm{WC} \geq 102 \mathrm{~cm}$ for men and $\geq 88 \mathrm{~cm}$ for women [18].

BP was measured after 15 minutes in the sitting position and in standardized conditions. Three consecutive BP measurements were taken at 5 minutes intervals using a validated automated sphygmomanometer (HEM-705 CP, Omron Corporation, Tokyo, Japan) with cuff's width adjusted to arm's circumference. A fourth measurement was obtained if the first three readings differed by $\geq 10$ mmHg. The averages of the nearest three BP and HR readings were considered in this study. Hypertension was defined as systolic BP $\geq 140 \mathrm{mmHg}$ and/or diastolic BP $\geq 90 \mathrm{mmHg}$, and/or ongoing antihypertensive medication [18].

Participants were instructed to fast for at least 8 hours overnight and FBG was determined using a glucometer (Accu-Chek Aviva, Roche, Mannheim, Germany). Diabetes and IFG were defined according to American Diabetes Association (ADA) criteria [19]. Diabetes mellitus was defined as FBG $\geq 126 \mathrm{mg} / \mathrm{dL}$ ( $\geq 7.0$ $\mathrm{mmol} / \mathrm{L}$ ) and/or being on glucose-lowering medication(s), while IFG was considered for FBG 100 - $125 \mathrm{mg} / \mathrm{dL}(5.6$ - $6.9 \mathrm{mmol} / \mathrm{L})$ in the absence of self-reported diabetes history.

\subsection{Statistical Analysis}

Continuous variables are presented as mean \pm 1 standard deviation (SD), and categorical data as percentages. Prevalence rates are presented with $95 \%$ confidence interval (CI). Prevalence rates were age-standardized according to Cameroon's age structure as for 2010 (13). The significance of differences between proportions was assessed using Chi squared test (for categorical variables), whereas the significance of differences between normally-distributed continuous variables was assessed using Student's t test. Multivariable logistic regression was used to assess the association between GHA, diabetes, or IFG and other va- 
riables. Odd ratios were adjusted for age, gender, and area of residence. Statistical significance was set at $\mathrm{p}<0.05$. All analyses were performed using SPSS 20 software (SSPS Inc, Chicago, Illinois, USA).

\section{Results}

\subsection{Baseline Characteristics of the Study Participants}

Eight hundred and eighty nine participants were recruited, of whom 461 (58.9\%) inhabited an urban area and 520 (58.5\%) were male. Characteristics of the study population are presented in Table 1 . The mean age of the study population was $39 \pm 15$ years, and there was no significant difference in mean age between the urban (38 \pm 14 years) and rural (39 \pm 15$)$ groups. Among all participants, 679 declared to be married (76.4\%), and 50 completed university level education (5.6\%), while 294 were uneducated (33.1\%) and 38 declared $\geq 200$ US\$ income/month (4.3\%). About 121 participants declared themselves as current alcohol drinkers (13.6\%), and 65 participants were current smokers (7.3\%). The prevalence of tobacco use, alcohol drinking, fruits/vegetable intake, and known diabetes was similar in the two groups. Urban dwellers had lower rates of regular physical activity, and higher figures regarding overweight/obesity, abdominal obesity, BMI, WC, FBG, systolic and diastolic BP, and HR.

\subsection{Prevalence of Glucose Homeostasis Abnormalities}

Table 2 shows the age-standardized prevalence (with 95\% CI) of overall GHA (IFG and diabetes), IFG, and diabetes, respectively. Data are presented according to age groups and gender, and compared between urban and rural areas. Among all participants, the prevalence (95\% confident interval) of GHA, IFG and diabetes were $33.3 \%(30.2 \%-36.4 \%), 21.7 \%(19.0 \%-24.4 \%)$ and $11.9 \%(9.9 \%-$ $14.1 \%)$, respectively. Results were similar between urban and rural areas for GHA $(\mathrm{p}=0.517)$, IFG $(\mathrm{p}=0.506)$ and diabetes $(\mathrm{p}=0.9)$ (Figure 1$)$. According to gender, prevalence of diabetes was $11.2 \%(8.5 \%-13.9 \%)$ in men vs $13.9 \%$ $(10.4 \%-17.4 \%)$ in women. In each group, the observed differences were not significant between gender, nor between urban and rural areas. The prevalence

of diabetes was significantly modulated by age, rising from $8 \%(5.5 \%-10.6 \%)$ in 18 - 34 years old participants to $20.5 \%(13.6 \%-27.3 \%)$ in 45 - 54 years-old participants, slightly decreasing to $16.1 \%(10.1 \%-22.1 \%)$ in older participants $(\geq 55$ years), $\mathrm{p}=0.0004$.

The prevalence of IFG was $20.4 \%(16.9 \%$ - $23.9 \%)$ in men, and $24.1 \%(19.7 \%$ $28.5 \%$ ) in women (Table 2). The differences in prevalence were not significant between urban and rural participants, although IFG prevalence was slightly higher in rural vs. urban women, at $28.2 \%(21.6 \%$ - 34.8\%) and $20.2 \%(14.5 \%$ $25.9 \%)$, respectively. The 35 - 44 years age-group had the highest prevalence of IFG, at $26.0 \%(19.5 \%-32.4 \%)$, while the $\geq 55$ years age-group had the lowest rate of IFG, at $17.5 \%(11.3 \%-23.7 \%)$.

Table 3 shows the prevalence of overall GHA, diabetes and IFG, respectively, 
Table 1. Baseline characteristics of study participants.

\begin{tabular}{|c|c|c|c|c|c|}
\hline & & $\begin{array}{c}\text { All } \\
(\mathrm{N}=889)\end{array}$ & $\begin{array}{c}\text { Rural } \\
(\mathrm{N}=428)\end{array}$ & $\begin{array}{c}\text { Urban } \\
(\mathrm{N}=461)\end{array}$ & $\mathrm{p}$ \\
\hline Age (years) & Mean \pm 1 SD & $39 \pm 15$ & $39 \pm 15$ & $38 \pm 14$ & 0.3 \\
\hline Male gender (\%) & & 58.5 & 58.9 & 58.1 & 0.8 \\
\hline \multirow[t]{2}{*}{ Marital status (\%) } & Married & 76.4 & 81.1 & 72 & \\
\hline & Unmarried & 23.6 & 18.9 & 28 & 0.002 \\
\hline \multirow[t]{4}{*}{ Education level (\%) } & None & 33.1 & 35.3 & 31 & \\
\hline & Primary & 29.9 & 29 & 30.8 & \\
\hline & Secondary & 31.4 & 32.5 & 30.4 & \\
\hline & University & 5.6 & 3.3 & 7.8 & 0.019 \\
\hline \multirow[t]{3}{*}{ Income (US\$) } & $\leq 100$ & 90.5 & 92.3 & 88.8 & \\
\hline & $100-200$ & 5.3 & 3 & 7.4 & \\
\hline & $>200$ & 4.3 & 3.9 & 4.7 & 0.032 \\
\hline \multirow[t]{2}{*}{ Alcohol intake (\%) } & None/former & 86.4 & 85 & 87.6 & \\
\hline & current & 13.6 & 15 & 12.4 & 0.33 \\
\hline \multirow[t]{2}{*}{ Tobacco use (\%) } & None/former & 92.7 & 93.2 & 92.2 & \\
\hline & current & 7.3 & 6.8 & 7.8 & 0.66 \\
\hline $\begin{array}{l}\text { Regular physical } \\
\text { activity (\%) }\end{array}$ & & 80.5 & 92.9 & 73.4 & $<0.0001$ \\
\hline \multirow[t]{2}{*}{ Fruits/vegetables } & $<5 /$ Day & 91.6 & 92.1 & 91.1 & \\
\hline & $\geq 5 /$ Day & 8.4 & 7.9 & 8.9 & 0.6 \\
\hline Weight (kg) & mean $\pm 1 \mathrm{SD}$ & $67.0 \pm 13.7$ & $69.7 \pm 33.5$ & $65.6 \pm 13.1$ & 0.018 \\
\hline Height $(\mathrm{cm})$ & mean $\pm 1 \mathrm{SD}$ & $168 \pm 9$ & $167 \pm 8$ & $168 \pm 9$ & 0.026 \\
\hline BMI $\left(\mathrm{kg} / \mathrm{m}^{2}\right)$ & mean $\pm 1 \mathrm{SD}$ & $23.8 \pm 4.5$ & $23.5 \pm 4.1$ & $24.1 \pm 4.7$ & 0.036 \\
\hline Overweight/obesity (\%) & & 31.3 & 28.0 & 34.3 & 0.04 \\
\hline Waist circumference $(\mathrm{cm})$ & mean \pm 1 SD & $81 \pm 13$ & $80 \pm 13$ & $83 \pm 13$ & 0.001 \\
\hline Abdominal obesity (\%) & & 15.3 & 11.9 & 18.4 & 0.009 \\
\hline Glycemia (mg/dL) & mean $\pm 1 \mathrm{SD}$ & $100 \pm 43$ & $97 \pm 25$ & $103 \pm 54$ & 0.02 \\
\hline $\begin{array}{c}\text { Family history of } \\
\text { diabetes }(\%)\end{array}$ & & 9.1 & 7.2 & 10.8 & 0.08 \\
\hline Systolic BP (mmHg) & mean $\pm 1 \mathrm{SD}$ & $134 \pm 22$ & $132 \pm 21$ & $136 \pm 23$ & 0.006 \\
\hline Diastolic BP (mmHg) & mean $\pm 1 \mathrm{SD}$ & $80 \pm 13$ & $78 \pm 11$ & $81 \pm 14$ & $<0.0001$ \\
\hline Hypertension (\%)* & & 37.8 & 34 & 41.2 & 0.8 \\
\hline Heart rate (bpm) & mean $\pm 1 S D$ & $82 \pm 25$ & $79 \pm 33$ & $84 \pm 15$ & 0.006 \\
\hline
\end{tabular}

BMI: Body mass index; BP: blood pressure; *age-adjusted prevalence of hypertension.

according to socio-demographic and clinical variables. Prevalence of GHA was significantly greater in married participants than single ones $(36.4 \%$ vs $25.2 \%$, $\mathrm{p}=0.003$ ). It was also significantly higher when overweight/obesity, abdominal obesity and hypertension were comorbid. Prevalence of IFG was significantly higher in participants with abdominal obesity $(31.6 \%$ vs $19.9 \%, p=0.003)$. 
Table 2. Prevalence of diabetes and prediabetes according to gender and age groups in urban and rural areas.

\begin{tabular}{|c|c|c|c|c|c|c|}
\hline & & & $\mathbf{N}$ & $\begin{array}{c}\text { GHA } \\
\%(95 \% \mathrm{CI})\end{array}$ & $\begin{array}{c}\text { IGT } \\
\%(95 \% \mathrm{CI})\end{array}$ & $\begin{array}{c}\text { Diabetes } \\
\%(95 \% \mathrm{CI})\end{array}$ \\
\hline \multirow{3}{*}{$\underset{\text { participants }}{\text { All }}$} & & Rural & 428 & $34.4(29.9-38.9)$ & $22.6(18.6-26.6)$ & $11.7(8.9-15.1)$ \\
\hline & & Urban & 461 & $32.0(27.7-36.3)$ & $20.6(16.9-24.3)$ & $12(9.0-15.0)$ \\
\hline & & All & 889 & $33.3(30.2-36.4)$ & $21.7(19.0-24.4)$ & $11.9(9.9-14.1)$ \\
\hline \multirow[t]{6}{*}{ Gender* } & Men & Rural & 252 & $29.2(23.6-34.9)$ & $18.5(13.7-23.3)$ & $10.7(6.9-14.5)$ \\
\hline & & Urban & 268 & $32.4(26.8-38.0)$ & $21.4(16.5-26.3)$ & $11.7(7.9-15.5)$ \\
\hline & & All & 520 & $31.2(27.2-35.2)$ & $20.4(16.9-23.9)$ & $11.2(8.5-13.9)$ \\
\hline & Women & Rural & 176 & $42.3(35.0-49.6)$ & $28.2(21.6-34.8)$ & $14.5(9.3-19.7)$ \\
\hline & & Urban & 193 & $32.6(26.0-39.2)$ & $20.2(14.5-25.9)$ & $13.3(8.5-18.1)$ \\
\hline & & All & 369 & $37.4(32.4-42.3)$ & $24.1(19.7-28.5)$ & $13.9(10.4-17.4)$ \\
\hline \multirow[t]{12}{*}{ Age groups } & $18-34$ & Rural & 211 & $31.3(25.0-37.5)$ & $23.2(17.5-28.9)$ & $8.1(4.4-11.7)$ \\
\hline & & urban & 226 & $28.3(22.4-34.2)$ & $21.2(15.9-26.6)$ & $8.0(4.4-11.5)$ \\
\hline & & All & 437 & $29.7(25.5-34.0)$ & $22.2(18.3-26.1)$ & $8.0(5.5-10.6)$ \\
\hline & $35-44$ & Rural & 89 & $44.9(34.6-55.3)$ & $32.6(22.8-42.3)$ & $12.4(5.5-19.2)$ \\
\hline & & urban & 88 & $36.4(26.3-46.4)$ & $19.3(11.1-27.6)$ & $17.0(9.2-24.9)$ \\
\hline & & All & 177 & $40.7(33.4-47.9)$ & $26.0(19.5-32.4)$ & $14.7(9.5-19.9)$ \\
\hline & $45-54$ & Rural & 68 & $36.8(25.3-48.2)$ & $17.6(8.6-26.7)$ & $20.6(11.0-30.2)$ \\
\hline & & urban & 64 & $39.1(27.1-51.0)$ & $20.3(10.5-30.2)$ & $20.3(10.5-30.2)$ \\
\hline & & All & 132 & $37.9(29.6-46.2)$ & $18.9(12.3-25.6)$ & $20.5(13.6-27.3)$ \\
\hline & $\geq 55$ & Rural & 60 & $30.0(18.4-41.6)$ & $11.7(3.5-19.8)$ & $18.3(8.5-28.1)$ \\
\hline & & urban & 83 & $36.1(25.8-46.5)$ & $21.7(12.8-30.6)$ & $14.5(6.9-22.0)$ \\
\hline & & All & 143 & $33.6(25.8-41.3)$ & $17.5(11.3-23.7)$ & $16.1(10.1-22.1)$ \\
\hline
\end{tabular}

Data are presented as prevalence (95\% confident interval); *age-standardized prevalence; GHA: glucose homeostasis abnormalities; IGT: impaired glucose tolerance.

Prevalence of diabetes was significantly higher in participants with marital condition, family history of diabetes, overweight/obesity, abdominal obesity and hypertension.

\subsection{Correlates of GHA}

Table 4 shows various correlates of overall GHA, diabetes and IFG according to demographic and other $\mathrm{CV}$ risk factors. Results are presented as odd ratio (OR) and $95 \% \mathrm{CI}$, with OR adjusted for age, gender and area of residence. Factors significantly associated to GHA were age, overweight/obesity, abdominal obesity and hypertension. Ageing, family history of diabetes, overweight/obesity, abdominal obesity and hypertension were associated with prevalent diabetes, while abdominal obesity was the sole correlate to IFG. After adjustment for age, gender and area of residence, all variables remained significantly associated with diabetes, except for married status, and abdominal obesity remained significantly associated with IFG. 
Table 3. Prevalence of GHA, IGT and diabetes according to demographic and clinical characteristics of the study.

\begin{tabular}{|c|c|c|c|c|c|c|c|}
\hline & & \multirow{2}{*}{$\begin{array}{l}\text { GHA } \\
\mathrm{N}(\%)\end{array}$} & \multicolumn{3}{|c|}{ IGT } & \multicolumn{2}{|c|}{ Diabetes } \\
\hline & & & $\mathrm{p}$ & $\mathrm{N}(\%)$ & $\mathrm{p}$ & $\mathrm{N}(\%)$ & $\mathrm{p}$ \\
\hline \multirow[t]{2}{*}{ Married } & no & $53(25.2)$ & & $43(20.5)$ & & $12(5.7)$ & \\
\hline & Yes & $247(36.4)$ & 0.003 & $150(22.1)$ & 0.689 & $99(14.6)$ & 0.001 \\
\hline \multirow[t]{4}{*}{ Level of education } & None & $102(34.7)$ & & $58(19.7)$ & & $45(15.3)$ & \\
\hline & Primary & $98(36.8)$ & & $71(26.7)$ & 0.3 & $28(10.5)$ & \\
\hline & secondary & $87(31.2)$ & & $55(19.7)$ & & $34(12.2)$ & \\
\hline & University & $13(26.0)$ & 0.331 & $9(18.0)$ & 0.131 & $4(8.0)$ & 0.259 \\
\hline \multirow{3}{*}{$\begin{array}{l}\text { Monthly incomes } \\
\text { (US\$) }\end{array}$} & $<50$ & $15(39.5)$ & & $9(23.7)$ & & $7(18.4)$ & \\
\hline & $50-200$ & $270(33.6)$ & & $175(21.8)$ & & $97(12.1)$ & \\
\hline & $\geq 200$ & $15(31.9)$ & 0.727 & $9(19.1)$ & 0.8 & $7(14.9)$ & 0.4 \\
\hline \multirow[t]{2}{*}{ Physical activity } & No & $115(33.7)$ & & $74(21.7)$ & & $41(12.0)$ & \\
\hline & Yes & $185(33.8)$ & 0.991 & $119(21.7)$ & 0.93 & $70(12.8)$ & 0.82 \\
\hline \multirow[t]{2}{*}{ smoking } & None/former & $281(34.1)$ & & $180(21.8)$ & & $105(12.7)$ & \\
\hline & current & $19(29.2)$ & 0.424 & $13(20.0)$ & 0.848 & $6(9.2)$ & 0.529 \\
\hline \multirow[t]{2}{*}{ alcohol } & None/former & $262(34.1)$ & & $168(21.9)$ & & $98(12.8)$ & \\
\hline & current & $38(31.4)$ & 0.558 & $25(20.7)$ & 0.855 & $13(10.7)$ & 0.634 \\
\hline \multirow{2}{*}{$\begin{array}{c}\text { family history of } \\
\text { diabetes }\end{array}$} & No & $266(32.9)$ & & $174(21.5)$ & & $95(11.8)$ & \\
\hline & Yes & $34(42.0)$ & 0.100 & $19(23.5)$ & 0.796 & $16(19.8)$ & 0.048 \\
\hline \multirow[t]{2}{*}{ overweight/obesity } & No & $185(30.3)$ & & $125(20.5)$ & & $61(10.0)$ & \\
\hline & Yes & $115(41.4)$ & 0.001 & $68(24.5)$ & 0.21 & $50(18.0)$ & 0.001 \\
\hline \multirow[t]{2}{*}{ abdominal obesity } & No & $232(30.8)$ & & $150(19.9)$ & & $85(11.3)$ & \\
\hline & Yes & $68(50.0)$ & $<0.0001$ & $43(31.6)$ & 0.003 & $26(19.1)$ & 0.016 \\
\hline \multirow[t]{2}{*}{ Hypertension } & No & $169(30.9)$ & & $121(22.1)$ & & $49(9.0)$ & \\
\hline & Yes & $131(38.3)$ & 0.023 & $72(21.1)$ & 0.7 & $62(18.1)$ & $<0.001$ \\
\hline
\end{tabular}

GHA: glucose homeostasis abnormalities; IGT: impaired glucose tolerance.

\section{Discussion}

We found a remarkable high rate of GHA in this cross-sectional populationbased study conducted among urban and rural dwellers of the Far-North region of Cameroon. Diabetes and IFG prevalence were similar between urban and rural participants, both in the overall population and in men or women subgroups. Despite numerous studies having been published worldwide on diabetes and IFG, very few of them emanated from SSA, let alone from Cameroon. To the best of our knowledge, no study so far assessed the prevalence of diabetes and IFG in the Far-North region of Cameroon, a disinherited area where most people are living in poverty and where the current health system is not tailored to face the rising burden of diabetes and CVDs [20].

Our findings confirm the unbridled increase in diabetes and IFG prevalence 
Table 4. Association of GHA, IGT and diabetes with demographic and others cardiovascular parameters.

\begin{tabular}{|c|c|c|c|}
\hline & GHA & IGT & Diabetes \\
\hline & $\begin{array}{l}\text { Adjusted OR (95\% } \\
\text { CI) }\end{array}$ & $\begin{array}{l}\text { Adjusted OR (95\% } \\
\text { CI) }\end{array}$ & $\begin{array}{l}\text { Adjusted OR } \\
\text { (95\% CI })\end{array}$ \\
\hline Urban area & $1.09(0.82-1.44)$ & $0.91(0.66-1.25)$ & $0.98(0.65-1.47)$ \\
\hline \multicolumn{4}{|l|}{ Age (years) } \\
\hline $18-34$ & 1 & 1 & 1 \\
\hline $35-44$ & $1.58(1.10-2.28)^{\mathrm{a}}$ & $1.21(0.81-1.82)$ & $1.94(1.13-3.33)^{\mathrm{a}}$ \\
\hline $45-54$ & $1.39(0.92-2.09)$ & $0.80(0.49-1.30)$ & $2.86(1.65-4.96)^{c}$ \\
\hline$\geq 55$ & $1.16(0.77-1.74)$ & $0.73(0.45-1.19)$ & $2.13(1.20-3.75)^{\mathrm{b}}$ \\
\hline Female gender & $1.25(0.94-1.66)$ & $1.17(0.85-1.62)$ & $1.24(0.83-1.87)$ \\
\hline Married & $0.68(0.46-1.00)$ & $1.09(0.70-1.68)$ & $1.80(0.92-3.55)$ \\
\hline \multicolumn{4}{|l|}{ Education level } \\
\hline None & 1 & 1 & 1 \\
\hline Primary & $1.28(0.62-2.61)$ & $1.40(0.92-2.13)$ & $0.86(0.50-1.47)$ \\
\hline Secondary & $1.55(0.77-3.09)$ & $0.90(0.57-1.44)$ & $1.23(0.70-2.16)$ \\
\hline University & $1.25(0.63-2.48)$ & $0.83(0.37-1.88)$ & $0.76(0.25-2.37)$ \\
\hline Physical activity & $1.08(0.80-1.47)$ & $0.96(0.67-1.36)$ & $1.40(0.90-2.17)$ \\
\hline Smoking & $0.87(0.49-1.54)$ & $0.88(0.46-1.68)$ & $0.84(0.34-2.07)$ \\
\hline \multicolumn{4}{|l|}{ income (US\$) } \\
\hline$\leq 100$ & 1 & 1 & 1 \\
\hline $100-200$ & $0.86(0.43-1.69)$ & $0.96(0.44-2.09)$ & $0.72(0.30-1.70)$ \\
\hline$>200$ & $0.79(0.32-1.95)$ & $0.80(0.28-2.30)$ & $0.84(0.26-2.70)$ \\
\hline Alcohol & $0.92(0.60-1.40)$ & $0.95(0.59-1.54)$ & $0.85(0.45-1.60)$ \\
\hline $\begin{array}{l}\text { Fruits/vegetables: } \\
\quad \geq 5 / \text { day }\end{array}$ & $0.95(0.70-1.29)$ & $1.17(0.82-1.67)$ & $0.88(0.58-1.35)$ \\
\hline $\begin{array}{c}\text { Family history of } \\
\text { diabetes }\end{array}$ & $1.44(0.90-2.30)$ & $1.13(0.65-1.94)$ & $1.78(1.07-3.25)^{\mathrm{a}}$ \\
\hline Overweight/obesity & $1.50(1.11-2.04)^{\mathrm{b}}$ & $1.24(0.87-1.76)$ & $1.66(1.09-2.53)^{\mathrm{a}}$ \\
\hline Abdominal obesity & $2.12(1.41-3.19)^{c}$ & $2.02(1.28-3.17)^{\mathrm{b}}$ & $1.43(1.04-2.45)^{\mathrm{b}}$ \\
\hline Hypertension & $1.39(1.03-1.88)^{\mathrm{a}}$ & $1.03(0.73-1.46)$ & $1.99(1.30-3.05)^{\mathrm{b}}$ \\
\hline
\end{tabular}

${ }^{\mathrm{a}}: \mathrm{p}<0.05{ }^{\mathrm{b}}: \mathrm{p}<0.01 ;{ }^{\mathrm{c}}: \mathrm{p}<0.001$; OR: odd ratio; CI: confident interval; OR are adjusted for age, gender and area of residence; GHA: glucose homeostasis abnormalities; IGT: impaired glucose tolerance.

previously described in Cameroon. In 1999, the prevalence of diabetes was $2 \%$ and $0.8 \%$ in urban and rural areas, respectively, while it was $6.06 \%$ in 2004 for the overall population [5]. Such rates are comparable to reported diabetes prevalence in SSA, ranging from $4.4 \%$ to $7 \%$ in 2013 [21], but are lower than what was found in the present survey. The high prevalence of diabetes found in the present study is at first glance contradictory with the low socioeconomic conditions and high occupational physical activity patterns reported for this area. This suggests that other environmental, biophysical or cultural factors (including low fruit \& vegetables and high-quality protein intakes; high saturated fat intakes; 


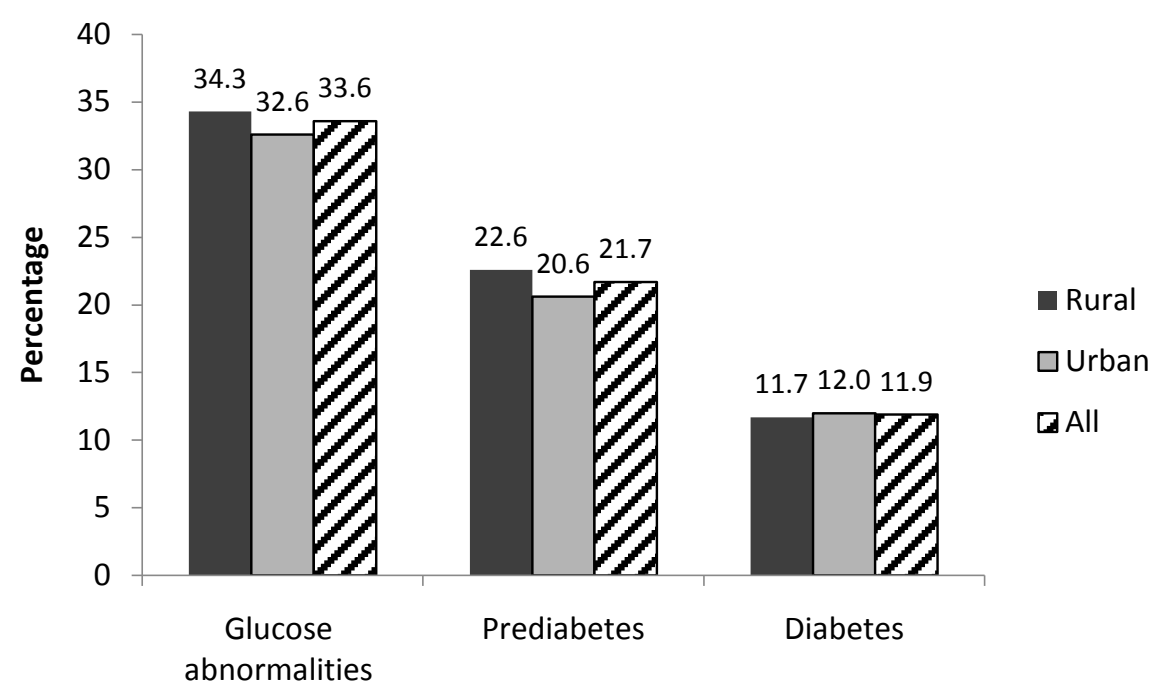

Figure 1. Age-standardized prevalence of glucose homeostasis abnormalities, prediabetes and diabetes between rural and urban participants.

overtly carbohydrate-based diets; body composition and ethnic susceptibility differences) may contribute to the unexpected high prevalence of GHA in this region, including rural areas.

Prevalence rates of comparable magnitudes were reported from Northern Africa, with an estimated of $13.8 \%$ for Algeria in 2010 [22], 9.9\% for Tunisia in 2007 [23], and $14.1 \%$ for Libya in 2001 [24]. Our results suggest that targeted programs are needed to improve education on a population basis, focusing on the importance of low fat and low glycemic index diet, as well as on increased fruits and vegetables consumption [25]. Our study shows an increased prevalence of diabetes and IFG from 18 - 34 years group to 45 - 54 years group, with a subsequent decrease in the $\geq 55$ years group, which may reflect a survival bias. The finding of a lower prevalence of diabetes in the 18-34 years age-group and a highest prevalence in the 45 - 54 years age-group is consistent with a previous report from Cameroon [26]. People in the 45 - 54 years age-group also suffer a higher rate of hypertension, abdominal obesity, and adiposity, all of which are comorbid and/or conducive to the common form of T2DM [27].

Studies on IFG in SSA, let alone in Cameroon, are very infrequent, and most studies cannot directly be compared to this study, due to discrepancies in the definition of IFG. In 2007, Kufe et al. [25] found an IFG prevalence of $5.7 \%$ in an urban setting of Cameroon using WHO/IDF criteria (FBG $\geq 110 \mathrm{mg} / \mathrm{dL}$ ). Using ADA criteria, the prevalence of IFG observed in this study was similar to data from Bangladesh (22.4\%) [28] and Uganda (20.2\%) [29], but was higher than the prevalence reported from South-Africa (9.9\%) [30]. In the present study, we found a strong prevalence of IFG, regardless of whether the participants came from urban or rural areas. Based on age, the highest prevalence was observed among 35 - 44 years participants, while the lowest prevalence was observed among the oldest age-group ( $\geq 55$ years). The higher prevalence of IFG observed 
in the younger age-group is a matter of concern, since the rate of conversion to T2DM is a function of time, and exposure to chronic hyperglycemia will start very early in some patients. Some meta-analyses suggest that lifestyle intervention can delay the risk of incident diabetes in patients with IFG for up to 10 years [31].

As expected, diabetes prevalence was significantly associated with age, family history of diabetes, overweight/obesity, abdominal obesity and hypertension while IFG was related to abdominal obesity. These results are consistent with previous epidemiological findings in the Cameroonian population [26] and in other African populations [29] [30] [32] [33]. These are priority groups which need to be targeted for more intense lifestyle education, with emphasis on increased physical activity, more balanced and diversified diets, self-monitoring of body weight, and regular FBG screening [29].

Considering the relationship between T2DM and hypertension, a recent hospital-based study in Cameroon shows a prevalence of T2DM and IFG of respectively $6.8 \%$ and $23.7 \%$ in newly-diagnosed hypertensive patients [34]. Likewise, the Framingham study showed that $6.3 \%$ of established hypertensive subjects had comorbid T2DM, compared to $4.3 \%$ of normotensive men and $2.1 \%$ of normotensive women [35]. The significant association of hypertension with T2DM, and not with IFG, found in this study suggests that some underlying determinants of hypertension may promote incident T2DM, particularly in patients with IFG. A link between increased odd of IFG and abdominal obesity confirms the involvement of the latter in driving insulin resistance and hyperinsulinemia, increased hepatic glucose output, fasting and postprandial hyperglycemia, and atherogenic dislipidemia [36]. Prolonged exposure to hyperglycemia may also accelerate conversion to T2DM as a result of glucotoxicity and promote long-term microvascular complications due to early exposure to hyperglycemia.

All this hints to an unmet need for preventive programs to promote healthier lifestyles and to initiate diabetes-screening campaigns.

\section{Strengths and Limitations}

The main limitation of this study was the limited sample size and the cross-sectional design, with, as a result, fairly large CIs for estimates. Further studies are needed, relying on larger samples size and also including other ethnic minorities from this region. Another limitation of the present survey is that, the prevalence of GHA might have been overestimated by the use of capillary blood sampling (Accu-Chek Aviva) to measure glycaemia. Indeed, although capillary glucose measured by a portable glucometer can provide valid approximation of blood glucose, it is, however, known to overestimate plasma glucose [37]. However, previous studies on GHA estimates in Cameroon and in other African countries used similar methods and prevalence can, therefore, be compared with our estimates. Strength of the present survey is its population-based design, and the use of validated standard procedures to assess the variables of interest. 


\section{Recommendations}

Our data make it possible to emit, in addition to the usual recommendations to detect diabetes as early as possible to prevent vascular complications, a practical message not to underestimate a priori the presence of unrecognized T2DM in rural areas, on the basis that the latter would be associated with a lower prevalence. In practice, it is necessary to re-emphasize more targeted screening of patients with a family history of diabetes and/or cardiometabolic comorbidities associated with T2DM, such as hypertension or android obesity, all the more so since these are easy to identify in routine.

\section{Conclusion}

Our findings show that glucose homeostasis abnormalities are alarmingly highly prevalent in rural and urban dwellers of the Far-North region of Cameroon, as compared to national diabetes prevalence. Diabetes and IFG rates were similar between urban and rural groups, and significantly increased with age, even though the figures slightly decreased somewhat beyond the age of 55. This survey also provides phenotypic markers for high-risk groups based on known risk factors for glucose homeostasis abnormalities, such as ageing, overweight/ obesity, abdominal obesity and hypertension. Risk-based interventions could be cost-effective as regards public health strategies to prevent incident diabetes in this population.

\section{Acknowledgements}

The authors express their grateful thanks to the survey officers, to all the participants to the survey, to the administrative and medical officers of the Farn North regional, to ULB-Erasme Hospital and to the Faculty of Medicine and Pharmaceutical Sciences of Douala University for continued support to epidemiological research on non-communicable diseases in Cameroon.

\section{Authors' Contributions}

$\mathrm{DL}, \mathrm{WN}$ and $\mathrm{MH}$ designed the study protocol, planned analyses, and wrote the first manuscript draft. CB led the statistical analyses and contributed data interpretation and to the manuscript drafting. DL, PA and $\mathrm{WN}$ contributed to data collection. $\mathrm{MH}$ critically contributed to analysis, discussion and interpretation of the data, and to the writing of the manuscript. PVB, ML, PD, NP and JPD contributed to data interpretation and the writing of the manuscript. All authors reviewed and approved the final manuscript draft.

\section{Disclosure of Interest}

The authors declare that they have no competing interest.

\section{References}

[1] Danaei, G., Finucane, M.M., Lu, Y., et al. (2011) National, Regional, and Global 
Trends in Fasting Plasma Glucose and Diabetes Prevalence Since 1980: Systematic Analysis of Health Examination Surveys and Epidemiological Studies with 370 Country-Years and 2.7 Million Participants. Lancet, 378, 31-40. https://doi.org/10.1016/S0140-6736(11)60679-X

[2] World Health Organization (WHO) (2016) Global Report on Diabetes. http://apps.who.int/iris/bitstream/10665/204871/1/9789241565257eng.pdf

[3] International Diabetes Federation (2013) IDF Diabetes Atlas. 6th Edition, Brussels.

[4] Shaw, J.E., Sicree, R.A. and Zimmet, P.Z. (2010) Global Estimates of the Prevalence of Diabetes for 2010 and 2030. Diabetes Research and Clinical Practice, 87, 20092014. https://doi.org/10.1016/j.diabres.2009.10.007

[5] Mbanya, J.C., Motala, A.A., Sobngwi, E., et al. (2010) Diabetes in Sub-Saharan Africa. Lancet, 375, 2254-2266. https://doi.org/10.1016/S0140-6736(10)60550-8

[6] Bansal, N. (2015) Prediabetes Diagnosis and Treatment: A Review. World Journal of Diabetes, 6, 296-303. https://doi.org/10.4239/wjd.v6.i2.296

[7] Maschirow, L., Khalaf, K., Al-Aubaidy, H.A. and Jelinek, H.F. (2015) Inflammation, Coagulation, Endothelial Dysfunction and Oxidative Stress in Prediabetes-Biomarkers as a Possible Tool for Early Disease Detection for Rural Screening. Clinical Biochemistry, 48, 581-585. https://doi.org/10.1016/j.clinbiochem.2015.02.015

[8] Bahar, A., Makhlough, A., Yousefi, A., et al. (2013) Correlation between Prediabetes Conditions and Microalbuminuria. Nephrourology Monthly, 5, 741-744.

https://doi.org/10.5812/numonthly.7646

[9] Allender, S., Lacey, B., Webster, P., et al. (2010) Level of Urbanization and Noncommunicable Disease Risk Factors in Tamil Nadu, India. Bulletin of the World Health Organization, 88, 297-304. https://doi.org/10.2471/BLT.09.065847

[10] Fezeu, L., Balkau, B., Sobngwi, E., et al. (2010) Waist Circumference and Obesity-Related Abnormalities in French and Cameroonian Adults: The Role of Urbanization and Ethnicity. International Journal of Obesity (London), 34, 446-453. https://doi.org/10.1038/ijo.2009.256

[11] Assah, F.K., Ekelund, U., Brage, S., et al. (2011) Urbanization, Physical Activity, and Metabolic Health in Sub-Saharan Africa. Diabetes Care, 34, 491-496. https://doi.org/10.2337/dc10-0990

[12] Sobngwi, E., Mbanya, J.-C.N., Unwin, N.C., et al. (2002) Physical Activity and Its Relationship with Obesity, Hypertension and Diabetes in Urban and Rural Cameroon. International Journal of Obesity, 26, 1009-1016. https://doi.org/10.1038/sj.ijo.0802008

[13] Cameroon's National Institute of Statistics (NIS) (2011) Statistics Year Book 2010. Chapter 4: Characteristics of the Population, 39-52. http://www.statistics-cameroon.org/downloads/annuaire2010/chap4.pdf

[14] Lemogoum, D., Van de Borne, P., Bika Lele, C.E., et al. (2017) Prevalence, Awareness, Treatment, and Control of Hypertension among Rural and Urban Dwellers of the Far North Region of Cameroon. Journal of Hypertension, 36, 159-168. https://doi.org/10.1097/HJH.0000000000001513

[15] World Health Organization (1998) Guidelines for Controlling and Monitoring the Tobacco Epidemic. World Health Organization, Geneva, 76-101.

[16] World Health Organization (WHO) (2011) Global Status Report on Noncommunicable Diseases 2010. World Health Organization, Geneva.

[17] Armstrong, T. and Bull, F. (2006) Development of the World Health Organization Global Physical Activity Questionnaire (GPAQ). Journal of Public Health, 14, 
66-70. https://doi.org/10.1007/s10389-006-0024-x

[18] Mancia, G., Fagard, R., Narkiewicz, K., et al. (2013) ESH/ESC Hypertension Guidelines for the Management of Arterial Hypertension: The Task Force for the Management of Arterial Hypertension of the European Society of Hypertension (ESH) and of the European Society of Cardiology (ESC). European Heart Journal, 34, 2159-2219. https://doi.org/10.1093/eurheartj/eht151

[19] American Diabetes Association (ADA) (2010) Standards of Medical Care in Diabetes-2010. Diabetes Care, 33, 11-61. https://doi.org/10.2337/dc10-S011

[20] Echouffo-Tcheugui, J.B. and Kengne, A.P. (2011) Chronic Non-Communicable Diseases in Cameroon-Burden, Determinants and Current Policies. Global Health, 7, 44. https://doi.org/10.1186/1744-8603-7-44

[21] Peer, N., Kengne, A.P., Motala, A.A. and Mbanya, J.C. (2013) Diabetes in the Africa Region: An Update. Diabetes Research and Clinical Practice, 103, 197-205. https://doi.org/10.1016/j.diabres.2013.11.006

[22] Abrouk, S. (2010) Descriptive Cross-Sectional Epidemiological Survey with Prospective Recruitment. National Institute of Public Health, Algiers. https://doi.org/10.1038/sj.ejcn.1602478

[23] Bouguerra, R., Alberti, H., Salem, L.B., et al. (2007) The Global Diabetes Pandemic: The Tunisian Experience. European Journal of Clinical Nutrition, 61, 160-165.

[24] Kadiki, O.A. and Roaeid, R.B. (2001) Prevalence of Diabetes Mellitus and Impaired Glucose Tolerance in Benghazi Libya. Diabetes \& Metabolism, 27, 647-654.

[25] Njamnshi, A., Hiag, Assumpta, B. and Mbanya, J.C. (2006) From Research to Policy: The Development of a National Diabetes Program in Cameroon. Diabetes Voice, $51,18-21$.

[26] Kufe, C.N., Klipstein-Grobusch, K., Fezeu, L., Assah, F., Ngufor, G., Mbeh, G., Mbanya, V.N. and Mbanya, J.C. (2015) Risk Factors of Impaired Fasting Glucose and Type 2 Diabetes in Yaoundé, Cameroon: A Cross-Sectional Study. BMC Public Health, 15, 59. https://doi.org/10.1186/s12889-015-1413-2

[27] Bray, G.A., Jablonski, K.A., Fujimoto, W.Y., Barrett-Connor, E., Haffner, S., Hanson, R.L., Hill, J.O., Van Hubbard, Kriska, A., Stamm, E. and Pi-Sunyer, F.X. (2008) Relation of Central Adiposity and Body Mass Index to the Development of Diabetes in the Diabetes Prevention Program. The American Journal of Clinical Nutrition, 87, 1212-1218.

[28] Akter, S., Rahman, M.M., Abeb, S.K. and Sultana, P. (2014) Prevalence of Diabetes and Prediabetes and Their Risk Factors among Bangladeshi Adults: A Nationwide Survey. Bulletin of the World Health Organization, 92, 204-213. https://doi.org/10.2471/BLT.13.128371

[29] Mayega, R.W., Guwatudde, D., Makumbi, F., et al. (2013) Diabetes and Pre-Diabetes among Persons Aged 35 to 60 Years in Eastern Uganda: Prevalence and Associated Factors. PLOS ONE, 8, e72554. https://doi.org/10.1371/journal.pone.0072554

[30] Shen, J., Kondaly, D., Rubinsteinz, A., et al. (2016) A Multiethnic Study of Pre-Diabetes and Diabetes in LMIC. Global Heart, 11, 61-70. https://doi.org/10.1016/j.gheart.2015.12.015

[31] Schellenberg, E.S., Dryden, D.M., Vandermeer, B., et al. (2013) Lifestyle Interventions for Patients with and at Risk for Type 2 Diabetes: A Systematic Review and Meta-Analysis. Annals of Internal Medicine, 15, 543-551.

[32] Chiwanga, F., Njelekela, M.A., Diamond, M.B., et al. (2016) Urban and Rural Prevalence of Diabetes and Pre-Diabetes and Risk Factors Associated with Diabetes in 
Tanzania and Uganda. Global Health Action, 9, Article No. 31440. https://doi.org/10.3402/gha.v9.31440

[33] Katchunga, P., Masumbuko, B., Belma, M., Kashongwe Munogolo, Z., Hermans, M.P. and M'Buyamba-Kabangu, J.R. (2012) Age and Living in an Urban Environment Are Major Determinants of Diabetes among South Kivu Congolese Adults. Diabetes \& Metabolism, 38, 324-331. https://doi.org/10.1016/j.diabet.2012.02.008

[34] Kamdem, F., Lemogoum, D., Doualla, M.S., Kemta Lepka, F., Temfack, E., Ngo Nouga, Y., Kenmegne, C., Luma, H. and Hermans, M.P. (2017) Glucose Homeostasis Abnormalites among Cameroon Patents with Newly Diagnosed Hypertension. The Journal of Clinical Hypertension, 19, 519-523. https://doi.org/10.1111/jch.12959

[35] Kannel, W.B. (1992) Potency of Vascular Risk Factors as the Basis for Anthy Pertensive Therapy. European Heart Journal, 13, 34-42.

https://doi.org/10.1093/eurheartj/13.suppl_G.34

[36] Jung, U.J. and Choi, M.S. (2014) Obesity and Its Metabolic Complications: The Role of Adipokines and the Relationship between Obesity, Inflammation, Insulin Resistance, Dyslipidemia and Nonalcoholic Fatty Liver Disease. International Journal of Molecular Sciences, 15, 6184-6223. https://doi.org/10.3390/ijms15046184

[37] Stauffer, F., Viswanathan, B., Jean, M., Kinabo, P. and Bovet, P. (2016) Comparison between Capillary Glucose Measured with a Contour Glucometer and Plasma Glucose in a Population Survey. Journal of Laboratory Medicine, 40, 133-139. 